\title{
Retraction Note to: An experimental study on microchannel heat sink via different manifold arrangements
}

\author{
Anurag Dahiya ${ }^{1} \cdot$ Mohammed Amer $^{2}$ (D) $\cdot$ Uzair Sajjad $^{2} \cdot$ Parismita Borah $^{3} \cdot$ Satbir Singh Sehgal $^{4} \cdot$ Harpreet Singh $^{4}$
}

Published online: 02 July 2021

(c) The Author(s) $2021 \quad$ OPEN

\section{Retraction Note to: \\ SN Applied Sciences (2020) 2:40 \\ https://doi.org/10.1007/s42452-019-1784-6}

The Publisher has retracted this article [1] because it shows significant overlap with a previous publication by some of the same authors without appropriate citation [2].

Author Mohammed Amer has agreed to this retraction but not to the wording of this retraction notice. Anurag Dahiya agreed to this retraction. None of the other authors responded to any correspondence from the editor or publisher about this retraction.

Open Access This article is distributed under the terms of the Creative Commons Attribution 4.0 International License (http://creativecommons.org/licenses/by/4.0/), which permits unrestricted use, distribution, and reproduction in any medium, provided you give appropriate credit to the original author(s) and the source, provide a link to the Creative Commons license, and indicate if changes were made. The Creative Commons Public Domain Dedication waiver (http:// creativecommons.org/publicdomain/zero/1.0/) applies to the data made available in this article, unless otherwise stated.

\section{References}

1. Dahiya A, Amer M, Sajjad U et al (2020) An experimental study on microchannel heat sink via different manifold arrangements. SN Appl Sci 2:40. https://doi.org/10.1007/s42452-019-1784-6

2. Dahiya A, Sehghal SS, Singh H (2017) Experimental studies of heat transfer analysis of microchannel heat sink through different manifold arrangements. In: Second thermal and fluids engineering conference. https://doi.org/10.1615/TFEC2017. mnt.018180

Publisher's Note Springer Nature remains neutral with regard to jurisdictional claims in published maps and institutional affiliations.

The original article can be found online at https://doi.org/10.1007/s42452-019-1784-6.

Mohammed Amer, mohammedamer.me03g@nctu.edu.tw| ${ }^{1}$ Department of Power Mechanical Engineering, National Tsing Hua University, Hsinchu, Taiwan. ${ }^{2}$ Department of Mechanical Engineering, National Chiao Tung University, Hsinchu, Taiwan. ${ }^{3}$ Department of Petrochemical Engineering, Gurukul Vidyapeeth Institute of Engineering and Technology, Punjab, India. ${ }^{4}$ Department of Mechanical Engineering, Chandigarh University, Punjab, India. 